\title{
THE TWENTY-SECOND REGULAR MEETING OF THE SAN FRANCISCO SECTION.
}

THE twenty-second regular meeting of the San Francisco Section of the Society was held at the University of California on October 26, 1912. About twenty persons were present, including the following members of the Society:

Mr. B. A. Bernstein, Professor H. F. Blichfeldt, Dr. Thomas: Buck, Professor G. C. Edwards, Professor L. M. Hoskins, Dr. Frank Irwin, Dr. C. G. P. Kuschke, Professor D. N. Lehmer, Professor J. H. McDonald, Professor W. A. Manning, Professor H. C. Moreno, Professor C. A. Noble, Professor E. W. Ponzer, Professor T. M. Putnam and Professor A. W. Whitney.

One session was held beginning at 10:30 A.M., Professor Hoskins, chairman of the section, presiding. The following officers were elected for the ensuing year: chairman, Professor Edwards; secretary, Professor Manning; program committee, Professors Manning, Noble, and Moreno.

It was voted to hold the next meeting at Stanford University on April 12, 1913. The members present lunched together after the meeting at the Faculty Club.

The following papers were presented at this meeting:

(1) Professor D. N. Lehmer: "On the expansion of the pure surd $R^{1 / \lambda}$."

(2) Professor A. W. Whitney: The representation upon a tetrahedron of the logical relations of two classes."

(3) Professor C. I. LEwis: "A new algebra of implications."

Professor Lewis was introduced by Professor Whitney.

Abstracts of the papers follow below.

1. The $n$th complete quotient of the surd $R^{1 / \lambda}$ being written in the form

$$
\frac{A_{n} R^{\frac{\lambda-1}{\lambda}}+B_{n} R^{\frac{\lambda-2}{\lambda}}+C_{n} R^{\frac{\lambda-3}{\lambda}}+\cdots+K_{n} R^{\frac{1}{\lambda}}+P_{n}}{Q_{n}},
$$

Professor Lehmer shows that the coefficients $A_{n}, B_{n}, C_{n}, \cdots$, $K_{n}, P_{n}$, and $Q_{n}$ are expressible as follows: 


$$
\begin{gathered}
A_{n}=\gamma^{\lambda-2}, \quad B_{n}=\alpha \gamma^{\lambda-3}, \quad C_{n}=\alpha^{2} \gamma^{\lambda-4}, \quad \cdots, \quad K_{n}=\alpha^{\lambda-2}, \\
(-1)^{n-1} Q_{n}=\alpha^{\lambda}-R \gamma^{\lambda},(-1)^{n} P_{n}=a^{\lambda-1} \beta-R \gamma^{\lambda-1} \delta,
\end{gathered}
$$

where $\alpha / \gamma$ and $\beta / \delta$ are the $n$th and $(n-1)$ th convergents in the expansion of $R^{1 / \lambda}$. Other remarkable relations between the coefficients are indicated.

2. From two logical classes can be developed a system of sixteen elements which is closed under the operations of logical addition, multiplication, and negation and forms a group under a certain other operation. Professor Whitney discusses this system and shows that it has a high degree of symmetry and that its internal structure is the same as that of a regular tetrahedron.

3. In the paper of Professor Lewis there is set up a revised system of implications in the algebra of logic which will exclude such doubtful theorems as "A false proposition implies any proposition" and "A true proposition is implied by any proposition." This system indicates that definitions in mathematics are relations of reciprocal implication, and that such relations can sometimes be deduced instead of assumed.

T. M. Putnam,

Secretary of theSection.

\section{THE FIFTH INTERNATIONAL CONGRESS OF MATH- EMATICIANS. SECTIONS II-IV.}

\section{Section II. Geometry.}

IN geometry, four sectional meetings were held, the chairmen being H. F. Baker, F. Severi, J. Drach and F. Morley. A. L. Dixon and E. Bompiani were elected permanent secretaries for all the sessions. The following papers were presented before this Section.

(1) Brouwer, L. E. J., Amsterdam: "Sur la notion de classe de transformations d'une multiplicité."

(2) Morley, F., Baltimore: "On the extension of a theorem due to W. Stahl."

(3) Eisenhart, L. P., Princeton: " Continuous deformation of surfaces applicable to quadrics." 